DOI 10.37882/2223-2982.2021.03.31

\title{
ЖИЛИЩНАЯ ПРОБЛЕМА МОСКВЫ НАЧАЛА 1950-Х ГОДОВ И ОСНОВНЫЕ НАПРАВЛЕНИЯ ЕЕ РЕШЕНИЯ ВНЕДРЕНИЕМ НОВОЙ ЖИЛИЩНОЙ ПОЛИТИКИ
}

\section{THE HOUSING PROBLEM OF MOSCOW IN THE EARLY 1950S AND THE MAIN DIRECTIONS OF ITS SOLUTION BY THE INTRODUCTION OF A NEW HOUSING POLICY}

D. Skripkin

Summary: The article considers the specifics of housing construction in Moscow during the "Khrushchev Thaw" (1953-1964). The directions of solving the housing crisis in Moscow are determined. The prerequisites for changes in the architectural appearance of the Russian capital, as well as political aspects that provoked urban planning reformations, are updated. The relationship between the doubling of the population of Moscow and the increase in the actual area of housing per person is studied. The foreign experience of construction of panel houses is considered. The article analyzes the negative features of the new housing policy of Moscow in 1953-1964, which consist in a decrease in the quality of housing under construction, as well as in the stratification of society provoked by the peculiarities of housing policy and increased control of the party nomenclature over the life of Muscovites. The positive aspects of the housing construction boom are outlined, as a result of which more than a third of Muscovites moved from unsuitable communal apartments, barracks, to separate apartments.

Keywords: housing policy, housing construction, "lowercase" building, "Khrushchev's layout", "Khrushchevki".

\author{
Скрипкин Дмитрий Дмитриевич \\ Аспирант, Московский городской \\ педагогический университет, \\ dimas-080594@rambler.ru
}

Аннотация: В статье рассмотрена специфика жилищного строительства в Москве периода «хрущевской оттепели» (1953-1964 гг.). Определены направления решения жилищного кризиса в Москве. Актуализированы предпосылки изменений в архитектурном облике российской столицы, а также политических аспектов, спровоцировавших градостроительные реформации. Исследована взаимосвязь между увеличением населения Москвы вдвое и ростом фактической площади жилья на одного человека. Рассмотрен зарубежный опыт строительства панельных домов. Проанализированы негативные черты новой жилищной политики Москвы 1953-1964 гг., заключающиеся в снижении качества строящегося жилья, а также в спровоцированном особенностями жилищной политики расслоении общества и повышении контроля партийной номенклатуры за жизнью москвичей. Обозначены позитивные аспекты жилищного строительного бума, в результате которого более трети москвичей переселились из непригодных для проживания коммунальных квартир, бараков, в отдельные квартиры.

Ключевые слова: жилищная политика, жилищное строительство, «строчная» застройка, «хрущевская планировка», «хрущевки».

Образование вошедшего в обиход советского человека термина, которым обозначались возведенные в период «хрущевской оттепели» (1953-1964гг.) дома и квартиры в них, связано с интенсификацией жилищного строительства в Москве, характеризующегося многократным приростом жилищного фонда, интенсификацией темпов возведения жилых микрорайонов с социально-ориентированной инфраструктурой. Если в 1950 году в Москве было сдано 500 тыс. кв. м. жилья, то в 1961 году это число выросло более чем 7 раз и составило 3700 тыс. кв. м.

Цель такового жилищного бума заключалась в реализации необходимости выведения населения поствоенной Москвы из бараков, землянок, коммунальных квартир, полуподвальных и ветхих непригодных или слабо 
пригодных к проживанию помещений, в которых жители столицы оказались в результате уничтожения более трети жилищного фонда во время Великой Отечественной войны.

Новая жилищная политика строилась на провозглашенном в 1956 г. во время XX съезда КПСС призыве о необходимости революционного изменения архитектурного облика столицы путем отхода от миллионных трат «на бессмысленное украшательство в угоду дурному вкусу некоторых архитекторов» [7] и лозунге «одна квартира на одну семью», развитому в Постановлениях ЦК КПСС и Совмина СССР «Об устранении излишеств в проектировании и строительстве»[3], «О развитии жилищного строительства в СССР»[2].

Однако же, как первое, так и второе не являются нововведением хрущевского периода, поскольку задача расселения коммунальных квартир и бараков провозглашалась в числе приоритетов жилищного строительства еще в сталинском Генплане 1935 г. [1], а дома-«хрущевки» по своему облику и планировке воспроизвели осуждаемую ранее как троцкистскую и чуждую советскому человеку архитектурную стилистику 20-х годов XX века.

В контексте общей успешности послевоенной индустриализации страны Н.С. Хрущев считал, что достижения тяжелой промышленности стоит применить и для решения жилищной проблемы. Он утверждал, что в случае перевода домостроения на индустриальную основу, каждый гражданин вскоре сможет получить достойное жилье. С этой целью он инициировал развитие типового строительства на основе крупных бетонных панелей. [11] Высокой эффективности этого метода надо было достичь благодаря скорости проектирования, изготовления конструкций и монтажа.

Ориентация на поквартирные заселения семей было существенным достижением после «коммуналки», где целая семья проживала в одной комнате или только имела свой «угол». [12] Н.С. Хрущев апеллировал не только к эстетическому и экономическому, но и к нравственному аспекту архитектурной профессии.

Непризнание осуществляемой в сталинский период застройки в стиле ампир с указанием на необходимость создания уникального лица российской столицы, отличного от европейских однотипных многоэтажек, было лишь одной из причин возвращения к постулатам постреволюционного стандартизированного строительства. Основными же причинами, как представляется, было активно реализуемое Н.С. Хрущевым развенчание культа личности И.В. Сталина с осуждением присущих его периоду управления государством подходов и взглядов. Способствовало отходу от сталинского классицизма и неприятие новым генсеком негласного принципа советской архитектуры дохрущевского периода: нужно строить именно так и никак иначе.

Логика обращения к архитектурному достоянию 20-х годов прошлого века связана также с ускорением и упрощением строительства, основанного на типичной схеме застройки. Приоритетом жилищной политики 50-х годов стало индустриальное стандартизированное жилое строительство с разбивкой территорий застройки на крупные кварталы и микрорайоны площадью до 60 га каждый, с размещением на их территории объектов социальной инфраструктуры: школы, детские сады и ясли, магазины и комбинаты бытового обслуживания, а также садово-парковых и спортивно-рекреационных объектов.

Такая организация территорий, новых и ранее существовавших, однако, в период жилищного бума активно застраиваемых микрорайонов была порождена идеей так называемого «города-сада», где многоэтажные дома и обслуживающие их объекты социальной инфраструктуры перемежаются с типичными сельскими ландшафтами. Однако уплотнение заселений и рост количества населения Москвы заставили отказаться от этой концепции, что, однако же, не помешало активному озеленению территорий и разбивке скверов, парков и садов на территории жилых районов.

Реализовывалась так называемая технология «строчной» застройки, в рамках которой все здания на территории жилого квартала или иного массива имели одинаковую ориентацию. Несмотря на внешнюю простоту и однообразие такой застройки, ее эффективность относительно организации территорий оказалась очень высокой.

«Строчная» застройка также способствовала удешевлению строительства и экономии ресурсов. При параллельном расположении домов кран мог работать одновременно на возведение конструкций двух зданий, что облегчало логистику и экономило трудовые и временные затраты.

Темпы прироста городского населения увеличивались и, принимая во внимание то, что развитие промышленности в исследуемый период предусматривалось на экстенсивной основе, а сам социально-политический режим в СССР несколько либерализовался, жилищный кризис неизбежно должен был обостряться. Уже летом 1953 г. на пленуме ЦК КПСС была зафиксировано катастрофичность проблемы жилья в стране: «Нет более острого вопроса, чем жилье. Конечно, продовольственный вопрос также острый <...>, но жилье! Жилье - это гораздо важнее» [4]. К началу исследуемого периода в 
составе жилищного сектора бараки составляли 9\% жилой площади городов, 54\% жилой площади не было оборудовано даже водопроводом, 59\% - канализацией. [8]

Исходя из указанного, перед новым руководством страны встал вопрос об укреплении собственного положения. С осознанием этого, придя к власти, Н.С. Хрущев именно массовое жилищное строительство поставил во главу угла социальной политики. При этом, очевидная несостоятельность все еще реализуемой в СССР практики жилстроя, не имевшая перспектив разрешить проблему перенаселения городов, побудила к поиску более дешевых и более производительных методов, в частности, связанных с обращением к мировому опыту обеспечения населения социальным жильем.

То, что сейчас нам известно, как индустриальное домостроение, столь активно реализуемое в середине XX в. в Советском Союзе, приобретало распространение как мировая тенденция в 1920-х гг.; при этом, еще в XVIII в. в США сборные здания из готовых элементов, благодаря легкости и скорости их возведения, использовались переселенцами. После Первой мировой войны минимализм среды и функциональность как архитектурная доминанта объединили в берлинской школе «Баухауз» столь известных специалистов, мэтров градостроительства Вальтера Гропиуса, Людвига Мис ван дер Роэ, Ле Корбюзье. В рамках поиска вариантов удовлетворения потребности широких слоев населения в обеспечении достойных жилищных условий с минимальными затратами, Мис ван дер Роэ разработал идею панельного дома - «платтенбау». «Баухауз» не прижилась в нацистской Германии, однако уже в 1933 г. интернационал незаурядных архитекторов со своими идеями разлетелся по миру. Так, идея платтенбау реализовалась сначала в Нидерландах; планировали строить платтенбау и руководители Третьего рейха - для поселенцев на «новых землях». В течение 1930-1940-х гг. индустриальные методы строительства с разной степенью успешности внедрялись в Нидерландах, Франции, Германии, особенно во время послевоенного восстановления государств; даже в Москве 1948 г. было построено несколько экспериментальных домов по различным технологиям, среди которых присутствовал и платтенбау в качестве трофейного проекта. Следует отметить, что ни один из них в то время не получил развития, хотя и рассматривались различные внедрения представленных технологий в широкое строительство - со стальным каркасом, железобетонным сборным каркасом, а в 1950 г. - и в формате возведения бескаркасных панельных домов. В развитых странах (к примеру, в США и Англии) по указанной технологии строили жилье для малоимущих или временное жилье для молодоженов, студентов, пожилых людей, особенно в период с 1947 г., когда Билл Хьюит в США применил в строительстве конвейерную сборку, апро- бированную изначально на строительстве одноэтажных блок-коттеджей.

Очевидно, что знакомство Н.С. Хрущева в зарубежных вояжах второй половины 1950-х гг. с проектами платтенбау и американским механизированным строительством привело к их объединению с отечественными разработками в советском варианте дешевого социального жилья.

Таким образом, главным катализатором массового строительства в СССР была политика Н.С. Хрущева, который, опираясь на зарубежный опыт возведения социального дешевого жилья, в т.ч. в формате внедрения технической конструкции платтенбау, а также, обратившись к довоенным конструктивистским идеям, авторы которых были репрессированы во время сталинского периода, Хрущев поставил жилищный вопрос первым на повестке дня и сумел добиться его высокой актуализации. Доклад Н.С. Хрущева «О широком внедрении индустриальных методов, улучшении качества и снижении стоимости строительства», провозглашенный 7 декабря 1954 г. на Всесоюзном совещании строителей и архитекторов, зарубежный исследователь А. Мартин (A. Martin) назвал одним из важнейших манифестов современной архитектуры.[11] В ходе указанного совещания, Н.С. Хрущев резко раскритиковал политику И.В. Сталина, социалистический реализм в архитектуре, а особенно - жилищное строительство этого периода, представленное в большей степени многоэтажными домами с просторными квартирами и орнаментированными фасадами, которое было доступным лишь для небольшого количества избранных, однако почти не уменьшило жилищный кризис в стране.[5]

В 1950-е гг. на ситуацию с жильем негативно повлияли следующие факторы (целостно и применительно к Москве):

- во многих городах жилой фонд был существенно поврежден во время войны; в Москве непосредственные повреждения и разрушения жилых зданий и помещений были связаны не с прямыми атаками неприятеля (за исключением отдельных, но не массированных авиаударов), а в большей степени с нехваткой финансовых и иных ресурсов на реконструкцию в ходе войны;

- доходные дома, которые составляли значительную часть жилого фонда, быстро выходили из строя из-за отсутствия обслуживания и перенаселенности - в соотносимой степени для всей РСФСР и Москвы.

Принципиальные вопросы жилищного строительства решались в Москве и апробировались там же в рамках актуализированного интенсифицированного вне- 
дрения проектов по жилой застройке. Были отвергнуты все другие индустриальные методы строительства и избран самый дешевый быстрый вариант «индустриальными методами на основе серийного производства»крупносборного строительства, в котором для экономии существенно сократили спецификацию элементов: сначала строили из кирпичных панелей с железобетонными перекрытиями, а затем из железобетонных панелей стали возводить и стенки; потолок был слишком низким (в первых сериях - 2,48 м, позже высота выросла до 2,502,55 м - это обосновывалось необходимостью экономии не только на объеме строительных материалов, но и на длине коммуникаций, а также на дальнейшем использовании коммунальных ресурсов для повседневного потребления); монтировались крошечные кухни (от 4-4,5 кв. м) и коридор, совмещенные и тесные санузлы, проходные комнаты и тому подобное. Квартиры в домах от одно- до трехкомнатных оборудовались газовыми плитами, а иногда и газовыми колонками. Малоэффективная, но дешевая теплоизоляция стен, а также достаточно слабая звукоизоляция между квартирами тоже способствовала экономии. Около 8\% стоимости сэкономили, не включив в планы строек лифты, однако пришлось учесть предостережения врачей, что без вреда для здоровья подниматься по лестнице следует не выше 5-го этажа. Еще немного удалось сэкономить, отказавшись от мусоропровода.

В целом, 1950-е гг. были периодом экспериментального проектирования и строительства, во время которого были отысканы архитектурно-конструктивные решения, испытаны новые материалы, способы изготовления и монтажа больших панелей, позволившие стандартизировать и максимально упростить возведение новых жилых помещений. Одной из первых и наиболее известных стала жилая серия К-7, разработанная инженером В. Лагутенко. Эта серия была воплощена в возведении пятиэтажных (сначала кирпичных, а затем панельных) домов без лифта и некоторых конструкторских элементов (мусоропровод непосредственно в подсобных помещениях квартир, наличие кладовок и прочее). Несмотря на то, что построенные в столь экономном режиме здания были спроектированы для нуклеарных семей и рассчитаны на семью из 2-3 человек, они часто становились пристанищем для шести или более лиц, за что «хрущевки» вскоре стали называть «трущобами» или «трущевками».

Упрощению подлежало и внутреннее устройство домов, и расположенные в них квартиры. В рамках принятого Совмина СССР "Об устранении излишеств в отделке, оборудовании и во внутреннем убранстве общественных зданий"[3] были приняты новые стандарты жилья. Кубатура «хрущевок» существенно снизилась в сравне- нии с квартирами сталинского периода: высота потолков уменьшилась с 3-3,5 м до 2,2-2,5 м, а площадь квартир сократилась примерно на четверть (жилая площадь однокомнатных квартир составляла всего 18-20 м², двух-

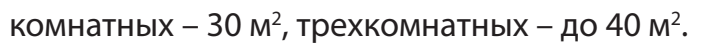

Стандартизировался и внутренний облик квартир: каждая квартира была оборудована кухней (в среднем

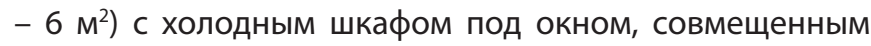
санузлом и подобием гардеробной комнаты (совмещенным со спальней помещением 2-2,5 м², в котором размещались встроенные полки), а также уменьшенном до физиологического минимума коридором. Типичная планировка квартир позволяла упростить и упорядочить также производство мебели, сантехники, текстильных ковровых и иных изделий.

В целях экономии ресурсов были сужены лестничные площадки и сами лестницы, а также исключены отдельные внутридомовые объекты общего пользования лифты, мусоропроводы; особым образом располагались почтовые ящики, что позволяло экономить внутреннее пространство домов.

Указанные меры позволили удешевить жилищное строительство на 35-40\%, что позитивно сказалось на количестве возведенных многоквартирных домов, которыми застраивались вновь разбитые и спроектированные микрорайоны. Экономия затрат на возведении жилья в рамках новой жилищной политики позволило к истечению первого десятилетия расселить из бараков, землянок, коммунальных квартир и иных слабо пригодных для проживания помещений более $30 \%$ москвичей.

Закономерно, что быстрое возведение жилых домов и сопутствующих объектов привело к снижению стандартов качества жилья, в результате чего износ жилья происходил ускоренными темпами в сравнении с ранее построенными объектами. Однако, несмотря на снижение качества строящегося жилья, его количество давало надежду на переселение в приемлемые условия проживания значительной части населения города. По меткому замечанию Н.С. Хрущева: «Да, трудно жить без лифта, но еще труднее без квартиры» [6].

В целом, жилищная политика в Москве 1953-1964 гг. характеризуется кардинальным приростом количества жилья. Снижение его качества компенсировалось временным характером построек, рассчитанных на 20-летнюю эксплуатацию. За указанный период не удалось полностью преодолеть жилищный кризис, однако удалось стабилизировать ситуацию, и теснота бараков, землянок, коммунальных квартир стала уделом не подавляющего большинства, а примерно трети жителей Москвы. 


\section{ЛИТЕРАТУРА}

1. Постановление СНК СССР, ЦК ВКП(б) от 10.07.1935 N 1435 "0 генеральном плане реконструкции города Москвы". // "СЗ СССР", 1935, N 35 , ст. 306.

2. Постановление ЦК КПСС, Совмина СССР от 31.07.1957 N 931 "0 развитии жилищного строительства в СССР". // "СП СССР", 1957, N 9, ст. 102.

3. Постановление Совмина СССР от 23.04.1959 N 449 "0б устранении излишеств в отделке, оборудовании и во внутреннем убранстве общественных зданий". // "СП СССР", 1959, N 8, ст. 55.

4. Стенограмма июльского (1953 г.) пленума ЦК КПСС. 2-7 июля 1953 г. // Лаврентий Берия. 1953. Стенограмма июльского пленума ЦК КПСС и другие документы. / Под ред. акад. А.Н. Яковлева; сост. В. Наумов, Ю. Сигачев. - М.: МФД, 1999. - С. 87-218.

5. Хрущев Н.С. О широком внедрении индустриальных методов, улучшении качества и снижении стоимости строительства: Речь на Всесоюз. совещании строителей, архитекторов и работников пром-сти строит. материалов, строит. и дор. машиностроения, проектных и науч.-исслед. организаций 7 дек. 1954 г. - М.: Госполитиздат, 1955. - 48 с.

6. Хрущев Н.С. Воспоминания. Время. Люди. Власть В 2-х книгах. - Кн. 1. - М.: Вече, 2016. - 912 с.

7. XX съезд Коммунистической партии Советского Союза. 14-25 февраля 1956 года. Стенографический отчет. Том 1. // Сборник документов и материалов цикла «КПСС в стенограммах, документах и материалах». - М.: Госполитиздат, 1956. - 640 с.

8. Боровикова 3.В. Развитие жилищно-коммунальной инфраструктуры Кемеровской области в 1946-1950 гг. // Вестник КемГУ. - 2019. - № 2 (78). C. 303-312.

9. Грудцына Л.Ю. Жилищная энциклопедия. - Система ГАРАНТ, 2008. - 385 с. [Электронный ресурс]. // Режим доступа: https://base.garant.ru/5488815/

10. Кузнецов С.А. Большой толковый словарь русского языка. - СПб.: Норинт, 2000. - 1536 с.

11. Мартин А. Идея прекрасного будущего. // Российский строительный каталог (Проект «Россия»): Архитектура, дизайн, градостроительство, технология. 2002. - № 3. - C. 6-11.

12. Шагов Н.В., Верёвкина И.Д., Кокшарова Е.А. Развитие типового жилищного строительства в советской России с 1917 по 1940 г. // Вестник МГСУ. - 2013. № 4. - C. 22-31.

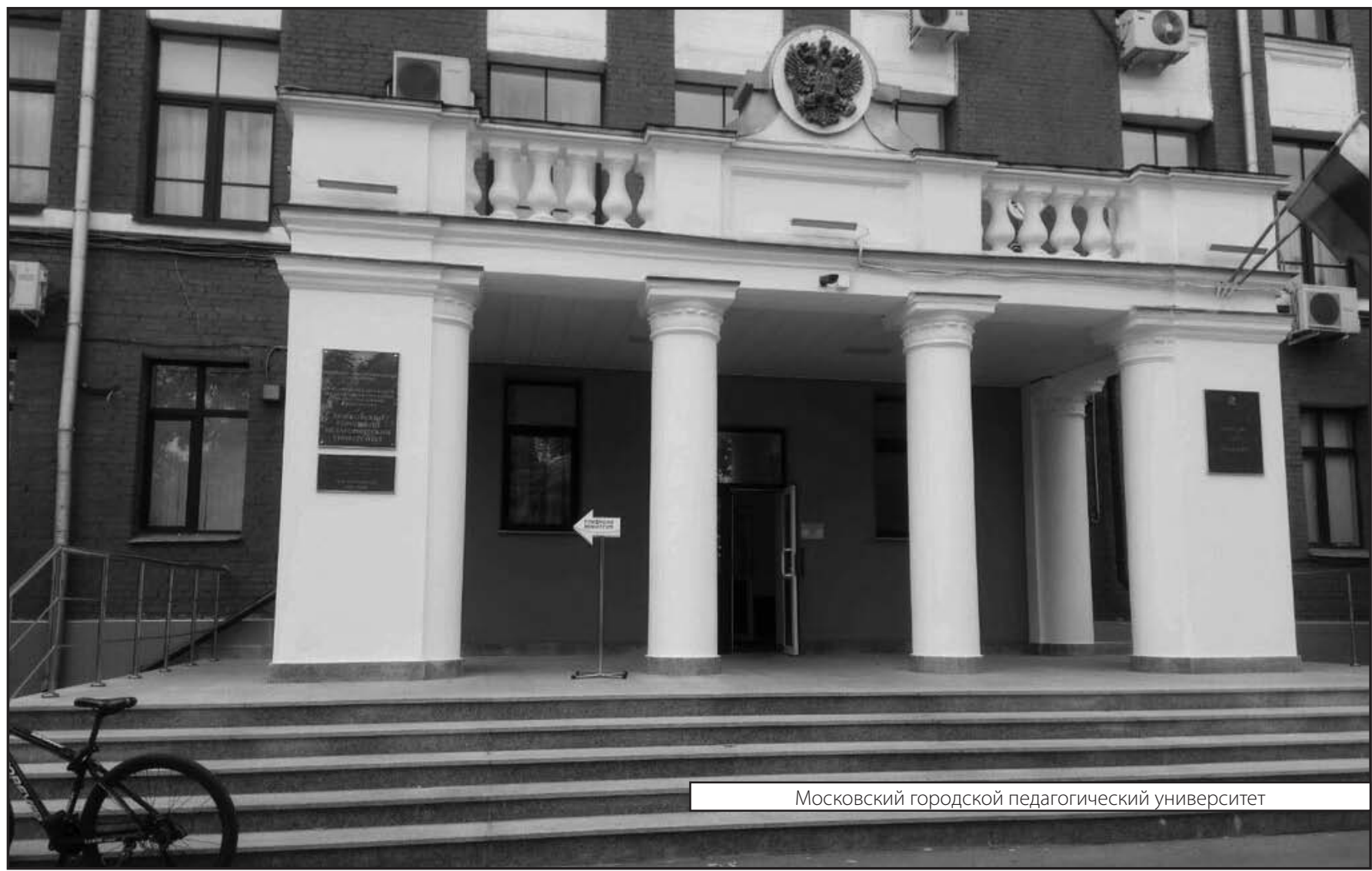

